Professor Lansbury is not required to like science, but if she wishes to write about it she does have a certain basic responsibility to her historical sources. My heart sinks when I see someone refer to Origin of the [sic] Species (p.154), as I think it is safe to assume that this person has not read, much less digested, Darwin's great work. My confidence is not strengthened when I discover Robert Koch referred to as a "physiologist", Claude Bernard (1813-1878) and Ferchault de Réaumur (1683-1757) described as "contemporaries", or Sir John Scott Burdon Sanderson rechristened "James". For Lansbury, as for nineteenth-century antivivisectionists, Claude Bernard was the chief spokesman for the new and vicious priesthood, intent on replacing the old values with the new gospel of materialism and science.

To give Professor Lansbury her due, she is aware that she has forsaken the subtle greys of historical analysis in favour of the blacks and whites of polemic: "Where emotions are the subject, quantification and statistics have proved notably deficient, and the historian is wise to defer to the poet and novelist". I doubt it. Elsewhere, she lays her cards on the table: "I know of only one law in history, and that is that people will always believe what they want to believe, despite all evidence to the contrary". This is profoundly depressing, but Lansbury's book makes me think it may be true.

W.F. Bynum is at the Wellcome Institute for the History of Medicine, 183 Euston Road, London $N W 12 B P, U K$.

\section{Mogi's doughnuts}

\section{Chi-Yu King}

Earthquake Prediction. By Kiyoo Mogi. Academic: 1985. Pp. 355. \$64, £53.50.

A VAST amount of information on earthquake prediction has accumulated in recent years, and has been published in several different languages in many different journals and reports. Under such circumstances, it has proved impossible for any individual to write a book on the subject that is coherent, comprehensive, up-to-date and without parochialism or personal bias. Mogi is not excepted.

The book has been translated from Japanese, with slight modification. It should, perhaps, have retained its original title, Earthquake Prediction - A Review of the Japanese Programme, for it mainly deals with material from Japan and Mogi's own research. Some of the older information has been covered by T. Rikitake in Earthquake Prediction (Elsevier, 1976), but much of the book contains newer data collected over the past decade. The translation retains a Japanese flavour, and some of the location maps are not labelled in detail so a familiarity with Japanese geography is helpful. A few technical terms (for example hypocentre, epicentre; dip, tilt) are used without discrimination. The quality of printing, however, is very good.

Mogi begins with a general discussion of the feasibility and physical basis of earthquake prediction, stressing the importance of crustal heterogeneity as a governing factor of precursor events and commenting on the success and failure of the dilatancy models and possible usefulness of the time-predictable and slippredictable models. He then describes prediction-related studies in various disciplines, covering crustal deformation, patterns of occurrence of smaller earth- quakes in space and time (including doughnut-shaped seismic gaps), seismicwave velocity changes, electromagnetic variations, groundwater and geochemical changes, active fault movement and laboratory observation of rock fracture. The coverage is not even-handed; much space is devoted to crustal movement and seismicity, little to hydrological and geochemical studies, and none at all to observations of anomalous light, fog and animal behaviour, or to engineering and socio-economic effects.

Next comes a detailed review of interdisciplinary observations of significant earthquakes that have occurred since 1965 , when the Japanese national programme on earthquake prediction began. Included here are accounts of the 1973 Nemuro-Hanto-oki earthquake (magnitude 7.4), the 1978 Miyagi-ken-oki earthquake (7.4), the 1983 Japan Sea earthquake (7.7), and the earthquakes that occurred along the Yamasaki fault and in and around the Izu region. Finally, Mogi describes the Japanese prediction efforts in the Tokai region, where a large earthquake is anticipated, and around Tokyo, and rounds things off with a discussion of strategy of long-term to short-term predictions.

The book contains no mathematics and relatively few technical details, and is thus suitable not only for experts but for nonspecialists looking for a coherent and upto-date account of Japanese work on earthquake prediction. Those who wish to know more about research going on elsewhere (notably in the Soviet Union, China and the United States), or in disciplines not well represented, will need to consult the proceedings of international symposia such as those published by the American Geophysical Union in 1981 and by Terra Scientific Publishing for UNESCO in 1984.

Chi-Yu King is at the US Geological Survey, 345 94025, USA. Middlefield Road, Menlo Park, California

\section{Looking for antigens}

\section{Julian Heath}

An Atlas of Immunofluorescence in Cultured Cells. By Mark C. Willingham and Ira Pastan. Academic:1985. Pp.186. $\$ 35, £ 31$.

IN recent years the use of fluorescentlylabelled antibodies to localize antigens in cells and tissues has been a prominent research tool for the cellular and molecular biologist. The compilation of an atlas of immunofluorescent images was therefore a good idea. But a truly comprehensive atlas would need to contain as many maps as there are antibodies, and would be a very. large tome indeed, so Willingham and Pastan have restricted themselves to the terrain with which they are most familiar. Their small volume contains images of cultured fibroblastic and epithelioid cells stained with antibodies to 26 cytoskeletal, membrane, nuclear and viral antigens, many of which they have used in their own research.

Although there is a 12-page introduction discussing specimen preparation for immunofluorescence, the overall feeling

\section{IMAGE \\ UNAVAILABLE FOR COPYRIGHT REASONS}

Immunofluorescence of the glomerular capsule showing the granular deposits of immunoglobulin characteristic of nephritis. The picture is taken from the new third edition of L.A. Sternberger's Immunocytochemistry, published by Wiley.

is of a subjective and rather self-indulgent account of this widely used technique. Moreover, the poor reproduction of some of the plates belies the word Atlas in the title. Clearer images with better contrast can often be found in the original papers, and in my review copy several pages were spoilt because print was visible through the page. It is also a great pity that there are no colour plates; fluorescence microscopy is visually very appealing with the range of fluors available, an atlas of black and white plates is not.

This is no hitch-hiker's guide to the galaxy of fluorescent images obtained by immunocytochemistry. But it is welcome as the first compendium of its kind, and will be a useful work of reference for those new to the field and for teaching purposes.

Julian Heath is in the Department of Biology, University of Pennsylvania, Philadelphia, Pennsylvania 19104, USA. 